FACULDADE DE CIÊNCIAS ECONÔMICAS DA UFRGS
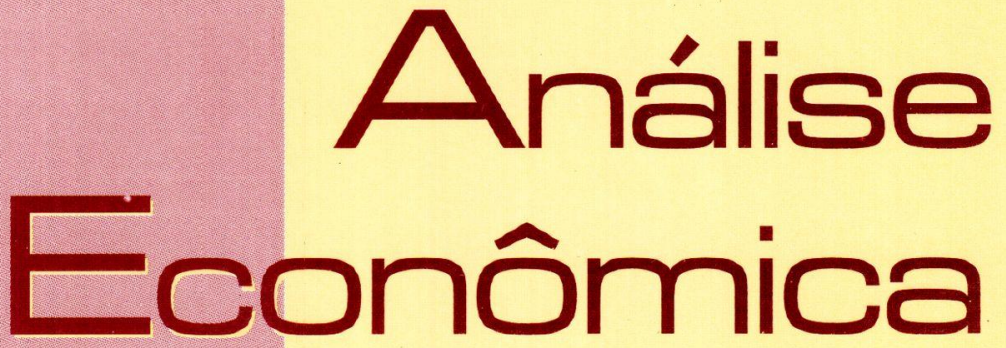

AS LOCOMOTIVAS ENFERRUIADAS

DO CAPITALISMO

Reinaldo Gonçalves

EFICIENNCIA, DESRECULAMENTACC̃O

FINANCEIRA E CRESCIMENTO

ECONOMICO: UMA ABORDAGEM

PÓS-KEYNESIANA

ROGÉRIO SOBREIRA

MERCADOS CONTESTÁVEIS E

COMPEIIÇÃO NO NOVO MODELO

DO SETOR ELÉtRICO BRASILEIRO

ELBIA VINHAES

EDVALDO SANTANa

MICROCRÉDITO: ASPECTOS TEÓRICOS

E EXPERIÊNCIAS

Márcio BobiK Braga

RUDINEI TONETO JR.

A RelaÇão Entre a Política e A ECONOMIA: SUAS IMPLICAÇÓES NO SISTEMA FINANCEIRO

JORGe PESSOA De MENDONĢA

AS RAiZzes CONCEITUAIS DO

INERCIALISMO

VAIDIR RAMAIHO

AUGE E INICIO DO DECLINIIO DA ECONOMIA ARGENTINA

maria Heló́sa lenz

$$
\text { ANO } \begin{array}{r}
18 \\
\text { No } 33
\end{array}
$$

MARÇO, 2000 
Universidade Federal do Rro Grande do Sui

Reitora: Prof ${ }^{a}$. Wrana Maria Panizzi

Faculdade de Ciências Econômicas

Diretora: Prof ${ }^{a}$ Otilia Beatriz Kroeff Carrion

Centro de Estudos e Pesquisas Econômicas

Diretor: Prof. Fernando Ferrari Filho

Departamento de Ciênctás Econòmicas

Chefe: Prof Luiz Alberto Oliveira Ribeiro de Miranda

Curso de Pós-Graduação em Economia

Coordenador: Prof. Marcelo Savino Portugal

Curso de Pós-Graduação em Economia Rural

Coordenador: Prof. Carlos Guilherme A. Mielitz Netto

Consel.ho Editorial:

Achyles B. Costa, Aray M. Feldens, Carlos A. Crusius, Carlos G. A. Mielitz Netto, Eduardo A. Maldonado Filho, Eduardo P. Ribeiro, Eugênio Lagemann, Fernando Ferrari Filho, Gentil Corazza, Marcelo S. Portugal, Nali I. Souza, Otnia B. K Carrion, Paulo A. Spohr, Paulo D. Waquil, Pedro C. D. Fonseca, Roberto C Moraes, Ronald Otto Hillbrecht, Stefano

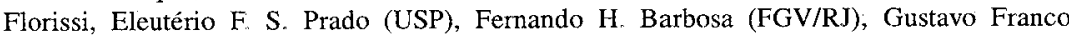
(PUC/RJ), João R. Sanson (UFSC), Joaquim P. Andrade (UnB), Juan H. Moldau (USP), Paul Davidson (Univ. of Tennessee), Werner Baer (Univ. of Illinois).

\section{Comissāo Entrorial:}

Eduardo Augusto Maldonado Filho, Fernando Ferrari Filho, Gentil Corazza, Marcelo Savino Portugal, Paulo Dabdab Waquil; Roberto Camps Moraes.

EorTor: Gentil Corazza

Edrror Adjunto: Pedro Silveira Bandeira

Secretário: Márcio Souza de Vargas

Revisão de Textos: Vanete Ricacheski

Fundador: Prof Antônio Carlos Santos Rosa

Os materiais publicados na revista Análise Econômica são da exclusiva responsabilidade dos autores. É permitida a reprodução total ou parcial dos trabalhos, desde que seja citada a fonte Aceita-se permuta com revistas congêneres. Aceitam-se, também, livros para divulgação, elaboração de resenhas e recensões. Toda correspondência, material para publicação (vide normas na terceira capa), assinaturas e permutas devem ser dirigidos ao seguinte destinatário:

PROF GENTIL CORAZZA

Revista Análise Econômica - Av. João Pessoa, 52

CEP 90040-000 PORTO ALEGRE - RS, BRASIL.

Telefones: (051) 316-3348 e 316-3440 - Fax: (051) 316-3990

E-mail: rae@vortex.ufrgs.br

Análise Econômica

Ano 18, $\mathrm{n}^{\circ} 33$, março, 2000 - Porto Alegre

Faculdade de Ciências Econômicas, UFRGS, 2000

Periodicidade semestral, março e setembro

1. Teoria Econômica - Desenvolvimento Regional -

Economia Agrícola - Pesquisa Teórica e Aplicada -

Periódicos. I. Brasil.

Faculdade de Ciências Econômicas,

Universidade Federal do Rio Grande do Sul. 


\title{
Mercados contestáveis e competição no novo modelo do setor elétrico brasileiro
}

\author{
Elbia Vinhaes* \\ Edvaldo Santana**
}

\begin{abstract}
Resumo: O modelo de reestruturação que vem sendo sugerido, e gradativamente implementado no setor elétrico brasileiro, tem, como um de seus pontos de sustentação, o princípio segundo o qual é possível promover a competição em segmentos potencialmente competitivos, como é o caso da geração de energia elétrica, e até mesmo em monopólios naturais, como é o caso da distribuição. Alguns pontos das mudanças ocorridas na indústria permitem que os grandes consumidores escolham de quem comprar a energia, não ficando na estrita dependência do distribuidor local e, assim, procurar melhores serviços e menores tarifas. O objetivo deste trabalho é mostrar, através da Teoria de Mercados Contestáveis (Baumol, et alii, 1982), se os instrumentos de regulamentação propostos pelo governo são capazes de assegurar a competição.
\end{abstract}

Palavras-chave: Competição, reestruturação e contestabilidade.

\begin{abstract}
The main goal of this work is show the major structural and institutional changes in Brazilian electrical sector. The model of restructuration that is suggested and gradually implemented on the Brazilian electric sector has as sustentation the principle that it is possible promote competition in segments potentially competitive like the electric energy generation and also in case of natural monopolies, as is the case of distribution. Using Contestable Market Theory proposed by Baumol et alii (1982) it is concluded that it is possible have competition in the segment of distribution and retail of energy and that the unbundling proposed by the government creates a contestability in this segment of the market, which has as new entrees the generation firms and the future energy trading firms.
\end{abstract}

Key-words: Competition, restructuration, contestability.

\footnotetext{
* Doutoranda em Engenharia de Produção EPS/UFSC, pesquisadora do NEIT/UFSC, professora da UNISUL.e-mail: vinhaes@cse.ufsc.br

** Professor Titular do Departamento de Economia e do CPGE/UFSC
} 


\section{Introdução}

Ainda que tenha um perfil de capacidade instalada bem diferente do que acontece em outros países, a indústria de energia elétrica brasileira com seu modelo de reestruturação vem seguindo a tendência mundial que, em linhas gerais, consiste na passagem de um modelo de monopólio para um mercado mais competitivo. Tal mudança tem ocorrido principalmente nos segmentos de geração e comercialização de energia, dado o pressuposto de que os segmentos de transmissão e distribuição são monopólios naturais. Entretanto, em alguns países, a depender das características da indústria como, por exemplo, da fonte de geração, a competição tem atingindo também os segmentos de distribuição. ${ }^{1}$

Os modelos de reestruturação têm seguido o arranjo britânico que, de maneira geral, tem na desverticalização, no aumento do número de competidores e na criação de um mercado spot as suas principais premissas para a busca da eficiência através da competição. Com muito poucas variações, esses foram os casos dos esquemas de reforma adotados na Argentina, Chile, Noruega, além da Inglaterra, e mais recentemente no Brasil.

Tais mudanças apresentam especificidades quando analisadas isoladamente e, num contexto geral, exceto o caso francês e o americano, têm seguido dois caminhos básicos: reestruturação e privatização. A primeira trata do arranjo comercial da indústria que, no caso específico da energia elétrica, está associada à desverticalização dos seus segmentos básicos e a segunda trata da mudança da propriedade estatal para a privada, tendo como fim último a mudança na propriedade e na gestão.

Desde 1995, a indústria de energia elétrica brasileira vem passando por uma reforma estrutural e institucional profunda. Seus principais atrativos são a busca do aumento da competição intra-setorial, a melhoria da qualidade e confiabilidade dọ serviços e a tentativa de estimular a entrada de capitais privados para viabilizar a sua expansão. O processo de reforma, destacando seus principais pontos de indefinição, limites e importância da atuação do órgão regulador, vem se intensificando - cita-se o estágio avançado do processo de privatização -, afetando a estrutura da indústria, a natureza da propriedade das suas empresas e os mecanismos de regulação. ${ }^{2}$

\footnotetext{
$1 \mathrm{Na}$ prática, o entendimento é de que os segmentos de geração e de comercialização devem ser expostos às "leis do mercado" e, para isto, tais atividades devem ser separadas das atividades de transmissão e distribuição, o que facilitaria o livre acesso ao sistema, reduzindo o poder de monopólio (regional) das empresas atualmente verticalizadas

2 O termo regulação e regulamentação são semelhantes para este trabalho. Maiores detalhes ver Vinhaes (1999).
} 
O desenho proposto pela Coopers \& Lybrand (consultoria britânica contratada para reestruturar o setor) tem como um dos seus pontos básicos o princípio segundo o qual é possível estimular a competição até mesmo nos segmentos considerados (em princípio) como monopólio natural, como seria o caso da distribuição/comercialização de energia elétrica, por exemplo. Isto visaria, entre outras coisas, estimular investimentos, melhorar a eficiência e criar as condições necessárias para a obtenção das demais vantagens que uma indústria competitiva pode oferecer.

Para reformar esta indústria, o modelo se pauta na combinação de três elementos básicos: privatização, competição e regulamentação. Entretanto, numa indústria com caráter de "rede", a introdução da competição não é possível por toda a extensão de seu mercado, dada a presença de monopólios naturais não contestáveis, ${ }^{3}$ conforme mencionado por Baumol et alii (1995). A idéia central do modelo proposto é a de que, para um alcance da eficiência econômica, um ambiente competitivo é preferível ao monopolista. $\mathrm{Na}$ ausência da concorrência, alguns estímulos devem ser dados às empresas para que suas estratégias se voltem para um melhor desempenho da indústria, sob a ótica do menor custo e do bem-estar social, e isso caberia ao órgão regulador.

A regulamentação econômica, neste caso, seria relevante para moldar a conduta das empresas no sentido de atingir eficiência produtiva e alocativa. Alguns mecanismos de regulamentação que têm sido utilizados estão orientados para a busca da eficiência produtiva, como é o caso do price-cap. Entretanto, tal mecanismo não tem se mostrado satisfatório em termos de eficiência alocativa. Outros instrumentos focalizam mais a eficiência alocativa (revenue cap), porém não são eficazes para incentivar a redução de custos. O que tem acontecido na maioria dos países é um misto destes dois instrumentos, sendo que, no caso brasileiro, a opção foi pelo regime de price-cap.

Um grande problema relacionado com a questão da eficiência, e que se reflete na regulamentação econômica, estaria associado ao preço a ser cobrado ao consumidor final, já que o órgão regulador precisa ordenar o acesso à rede e regular as tarifas cobradas para o uso das redes. Neste sentido, é importante que se discuta a relação custo do livre acesso e o grau de competição daí decorrente para destacar os efeitos da competição potencial e efetiva sobre a eficiência da indústria.

\footnotetext{
${ }^{3}$ Os monopólios naturais não contestáveis são chamados de monopólios auto-sustentados, ou seja, que não necessitam de regulamentação second best para sua sustentação, pois possuem uma eficiência ótima de escala por toda a faixa de produção Baumol et alii (1982).
} 
Este trabalho analisa os principais aspectos da reestruturação da indústria de energia elétrica brasileira, verificando os possíveis efeitos das mudanças nos quatro segmentos da indústria (geração, transmissão, distribuição e comercialização), e mostra através da Teoria de Mercados Contestáveis, proposta por Baumol et alii (1985), se os instrumentos da reforma são suficientes para estimular a competição na indústria, principalmente no segmento de comercialização (varejo) de energia, assim como as conseqüências microeconômicas das interações entre os quatro segmentos. Nessa perspectiva, destaca ainda, conforme Armstrong \& Vickers (1996), a regra do componente preço eficiente, ou regra de Baumol \& Willing, sugerindo um nível de preço a ser praticado na indústria. A seção um apresenta esta introdução, a seção dois, referencial teórico, faz algumas reflexões sobre a regulamentação dentro de um ambiente de reestruturação, destacando a Teoria de Mercados Contestáveis, principal referencial analítico deste trabalho. A seção três, reestruturação e contestabilidade, mostra os principais resultados da análise da competição através da Teoria de Mercados Contestáveis. A seção quatro destaca o problema do preço da ser cobrado ao consumidor final e sugere a regra de preço eficiente ( op cit). A seção cinco apresenta as considerações finais.

\section{Restrułuração e regulamentação}

A regulamentação, de um modo geral, atinge desde os mercados competitivos, estabelecendo padrões mínimos de qualidade ou controlando a oferta do produto, até os mercados monopolistas auto-sustentados e contestáveis. ${ }^{4}$ As indústrias de rede são um exemplo de utilities que foram tradicionalmente constituídas por monopólios verticalmente integrados e, com isso, as firmas conquistaram distintas vantagens técnicas e financeiras, normalmente empregadas para subsídios cruzados, canalizando recursos de atividades de mercados não-competitivos para atividades de mercados competitivos (Gomes, 1997), o que tradicionalmente aconteceu à indústria de energia elétrica brasileira. Esse tipo de conduta pode se constituir em barreiras à entrada de competidores, que não podem desfrutar das vantagens conquistadas pelas firmas preestabelecidas.

Com o processo de desverticalização (unbundling) da indústria de energia elétrica brasileira, o órgão regulador em geral procura separar as atividades upstream, midstream e dowstream da cadeia produtiva, detectan-

\footnotetext{
${ }^{4}$ A regulamentação segue parâmetros tradicionais ao verificar a existência de monopólios naturais, sob a ótica de economia de escala. Conforme Possas et alii (1997), isto se dá de duas maneiras básicas: reativa, relacionada à estrutura de mercados potencialmente competitivos, e ativa, relacionada à estrutura de mercado com monopólio naturais, como é o caso da infra-estrutura (utilities).
} 
do possíveis mercados contestáveis onde a competição possa efetivamente ocorrer (Gomes, 1997). O problema é saber se a indústria pode operar de forma mais eficiente (com menores custos e maiores benefícios energéticos) de forma desverticalizada, como está propondo o governo. Isto é, uma vez que as atuais distribuidoras estão sendo segregadas em distribuidoras e comercializadoras, a operação separada dos ativos de transmissão vai ocasionar uma intensificação das relações comerciais entre as empresas a montante e a jusante e até mesmo na horizontal. Na ótica da Economia dos Custos de Transação, estas relações podem aumentar os custos e ainda não gerar os efeitos esperados em termos de competição (Oliveira, 1998).

Destaca-se, ainda, a importância de se criar um ambiente seguro e estável, onde os investidores possam sentir confiança em depositar seu capital. Neste sentido, o órgão regulador precisa ser independente e adotar uma postura ativa, e não apenas estabelecer as regras necessárias para o funcionamento deste mercado, bem como aplicá-las efetivamente, sem incorrer em riscos regulatórios e nem gerar ineficiência (Gomes, 1997). Uma questão que tem sido sugerida e se mostrado eficiente é uma maior liberdade naqueles segmentos onde a competição tem se tornado possível, de modo que os mesmos, quando submetidos a um ambiente competitivo, não necessitariam de um regime regulatório tão rigoroso, como sugerido por Baumol \& Sidak (1995) com base na Teoria de Mercados Contestáveis.

A Teoria dos Mercados Contestáveis desenvolvida por Baumol et al. (1982) pressupõe uma série de hipóteses, dentre as quais a inexistência de sunk costs, barreiras à entrada/saída, economias de escala e escopo. Ao papel da concorrência potencial, é dada grande importância, mesmo na presença de fortes economias de escala, suficientes para justificar o monopólio ou o oligopólio como estruturas que minimizam custos. A concorrência potencial, neste caso, impede que as firmas estabelecidas ou incumbentes realizem lucros de monopólios, sob pena de serem vítimas de uma entrada. A conseqüência desta suposição é que um monopólio pode, em princípio, ser contestável.

Segundo Baumol \& Sidak (1995), a Teoria dos Mercados Contestáveis objetiva fornecer um quadro de referência mais amplamente aplicável para ser utilizado pelas agências reguladoras e tribunais nas questões referentes ao bem-estar. Não acreditam, portanto, que o mercado livre resolve automaticamente todos os problemas econômicos e que virtualmente todas as atividades reguladoras e antitruste constituem uma fonte onerosa de ineficiência econômica. Neste caso, não só os custos, o desempenho e a conduta das empresas serão afetadas pela regulamentação. A estrutura de mercado também pode ser alvo de atos regulatórios, principalmente nos setores de infra- 
estrutura, onde tradicionalmente domina a forma de monopólios. Algumas ações regulatórias podem servir para quebrar as barreiras à entrada de novos concorrentes, facilitando práticas competitivas.

Se a regulamentação de mercado de um determinado setor da economia deve seguir um modelo, então Baumol \& Sidak (1995) propõem que este modelo deve ter como base a Teoria dos Mercados Contestáveis, já que esta é menos restritiva e poderia contribuir de forma mais significativa, na medida em que propõe mudanças que podem ser chamadas de desregulamentação parcial, flexibilidade da regulamentação, ou ambas.

Um dos objetivos da restruturação da indústria de energia elétrica brasileira pode ser entendido como o de promover a competição em mercados contestáveis. Nesse sentido, alguns segmentos desta indústria deixarão de funcionar em regime monopolista (como seria o caso da comercialização e da geração de energia), o que será discutido na próxima seção.

\section{Reestrułuração e contestabilidade}

No Brasil, os sistemas elétricos são interligados e sob o ponto de vista das fontes geradoras, as relações entre os consumidores finais e as usinas são "virtuais", dado que não há como identificar fisicamente a origem da energia que está sendo consumida. Como acontece em todos os sistemas que atuam sob a forma de pool, neste caso, a seleção da empresa que deve supri-los passa a ser entendida como um exercício de análise financeira, haja vista que o relacionamento entre comprador e vendedor é meramente financeiro (Santana \& Oliveira, 1998). O segmento de geração, até o modelo comercial anterior, foi considerado como monopólio, devido às grandes economias de escala, fortes barreiras à entrada/saída e à necessidade de grandes investimentos nos ativos. No novo modelo, a possibilidade de entrada de produtores independentes e de co-geradoras vão de alguma maneira contribuir para o aumento da competição na geração. Ademais, a entrada de novas fontes de geração, como é caso das termelétricas a gás natural, poderá aumentar ainda mais a concorrência. Contudo, em virtude da predominância das fontes hidráulicas de geração, aspecto peculiar do Brasil, dificilmente o grau de competição chegaria ao nível do alcançado na Inglaterra, Chile e Argentina, que tem semelhanças com o novo modelo brasileiro, mas com fontes de geração diferentes.

Assim, no novo modelo brasileiro, a competição na geração vai continuar de forma predominantemente pelo mercado, ${ }^{5}$ através da licitação para

\footnotetext{
${ }^{5}$ A discussão da competição no mercado e pelo mercado foi apresentada por Possas et alii (1996) e diz resumidamente o seguinte: se a competição entre as firmas não é possível, cabe ao órgão regulador praticá-la através de leilão para concessões de nova usinas.
} 
explorar as grandes usinas, com importante interferência do órgão regulador. Neste sentido, apesar de haver um certo grau de competição efetiva, a existência de economias de escala/escopo relevantes, os sunk costs, as barreiras à entrada/saída e um forte elemento de coordenação neste segmento, não cogitaria a hipótese de contestabilidade. Ou seja, sob a ótica da Teoria dos Mercados Contestáveis, o papel da concorrência potencial não seria relevante.

$\mathrm{Na}$ transmissão, devido ao caráter "rede" deste segmento, aos vultosos investimentos e às economias de escala e escopo, a competição não se mostra possível e muito menos desejável. O caráter "rede" sugere que este segmento permaneça nas mãos de um proprietário estratégico, que possa ofertar o "serviço" em forma de utilities. Ou seja, deveria permanecer como monopólio estatal, sob a forma de bem público. Este é o ponto comum apresentado na reestruturação da indústria em diversos países: a transmissão tem sido considerada por todos os modelos como um monopólio natural. Destaque-se, ainda, que, neste segmento, a coordenação é um forte elemento, o que, portanto, restringe a hipótese de competição potencial e principalmente efetiva.

No segmento de distribuição/comercialização ${ }^{6}$ de energia elétrica, objeto central deste trabalho, ressaltam-se alguns elementos fundamentais para discutir a contestabilidade, dentre estes: a criação da figura do produtor independente de energia; o livre acesso às redes de transmissão e distribuição; a criação do mercado de atacado de energia (MAE); e, principalmente, a criação da categoria de consumidor livre.

O sistema elétrico brasileiro tem uma característica que é fundamental para o estímulo à competição no segmento de distribuição/comercialização de energia. A saber, o sistema elétrico Sul/Sudeste/Centro-Oeste é fortemente interligado e há uma coordenação centralizada da geração de tal sistema. Desse modo, a energia recebida, por exemplo, por um consumidor do Espírito Santo tem o mesmo nível de qualidade (técnica) da energia que está sendo consumida em Santa Catarina. Dessa forma, se não há qualquer limitação de acesso às redes de transmissão e de distribuição (tanto para as usinas quanto para os consumidores), então é uma idéia bastante interessante permitir que este últimos possam escolher os seus fornecedores de energia. Ora, se esta escolha é possível, então o mercado (por exemplo) da Celesc, comercializadora de energia em Santa Catarina, pode ser considera-

\footnotetext{
${ }^{6}$ No Brasil as atividades de comercialização de energia eram realizadas juntamente com a distribuição. Com o novo modelo haverá separação, sendo que a comercialização tem sido considerada como potencialmente competitiva, uma vez que o comercializador não precisa dispor de ativos físicos para vender energia.
} 
do como contestável, por geradoras, por outras distribuidoras atuando fora da sua área de concessão e por empresas de comercialização de energia.

A rigor, a mesma empresa que vende energia em Minas Gerais pode também ter consumidores no Rio Grande do Sul e, para isto, não precisa ter qualquer instalação de geração ou de distribuição no Rio Grande Sul. Basta que lhe seja dado o livre acesso às redes. Um mercado com estas características, resolvido o problema dos sunk costs, é um mercado contestável, isto é, onde há uma competição potencial entre diversos agentes. Observe-se que, num mercado assim considerado, deixaria de existir também o monopólio regional das geradoras (que venderiam energia em grosso para as distribuidoras mais próximas, como a antiga Eletrosul, que vendia energia para a Celesc, em Santa Catarina, para a CEEE, no Rio Grande do Sul, e para a Enersul, no Mato Grosso do Sul).

A partir das mudanças ocorridas na indústria, os grandes consumidores também ganharam o direito de escolher' de quem comprar a energia, não ficando na estrita dependência do distribuidor local e, assim, procurar melhor serviço, menores tarifas e demais vantagens da concorrência. Da mesma forma, a criação da figura do produtor independente (empresa apenas geradora de eletricidade), além de facilitar um certo grau de concorrência no segmento de geração, favorece a contestabilidade na distribuição/comercialização, uma vez que o consumidor livre poderá comprar direto da geradora (os novos geradores poderão vender diretamente para os grandes consumidores). ${ }^{\text {? }}$

Desse modo, em sistemas interligados (pool de geradores) e onde o acesso à rede é livre, a competição entre geradores (produtores independentes e co-geradores) é mais facilmente alcançada. Além disso, é facilitada a concorrência no segmento de comercialização (varejo). Na realidade, o produtor independente e o co-gerador são entrantes potenciais na venda de energia para um dado consumidor (livre) final ${ }^{8}$. Assim, o livre acesso, juntamente com o estímulo à competição na geração de energia, gera uma concorrência potencial nesta indústria, visto que o custo de transporte da energia será equalizado no país. Fica claro, portanto, a quebra do monopólio natural, pelo menos para grandes consumidores.

Tal como pressuposto na Teoria de Mercados Contestáveis, os elementos-chave para tratar da concorrência potencial na indústria de energia elétrica brasileira estão associados, principalmente, aos sunk costs e às barrei-

\footnotetext{
${ }^{7}$ Ou seja, sutilmente se percebe a contestabilidade nessa indústria onde um segmento interfere sobre outro.

${ }^{8}$ No início, aqueles acima de $10 \mathrm{MW}$ atendidos sob tensão acima de $69 \mathrm{kV}$ e a partir do ano 2000 acima de $3 \mathrm{MW}$ e, finalmente, até chegar a $500 \mathrm{~W}$ para os consumidores industriais.
} 
ras à entrada/saída. Na verdade, na inexistência desses elementos, isto é, onde há saída sem custos, inexistência de sunk costs e inexistência de barreiras à entrada, a firma pode sair ${ }^{9}$ livremente do mercado, sem as perdas financeiras dos ativos investidos. ${ }^{10}$

Além disso, mesmo que uma dada empresa venha a perder parte de seus consumidores livres para outras é possível que, em um prazo relativamente curto, ela consiga alocar seu excedente de energia - decorrente da ação do novo entrante - para atendimento de novos consumidores cativos. Se, por outro lado, a empresa incumbente é uma puramente comercializadora, a mesma não teria ativos dedicados ${ }^{11}$ - a não ser medidores -, portanto, quase não existiria custos irrecuperáveis. Em outras palavras, se a firma incumbente é uma distribuidora, os custos de saída seriam inversamente proporcional à taxa de crescimento do mercado e de seus consumidores cativos. Adicionalmente, visto que o acesso às redes é livre e como os sistemas são interligados, a empresa incumbente (que ocasionalmente perdeu parte do mercado) poderá ganhar novos mercados (novos consumidores), o que significa reutilização imediata da capacidade instalada.

Em princípio, os sunk costs seriam elevadíssimos no segmento de distribuição. Entretanto, com a desverticalização (através da criação das empresas retalliers, varejistas ou comercializadoras) esses custos ficam bastante reduzidos, uma vez que as comercializadoras de energia são "firmas de escritório", em geral sem propriedades de ativos de geração, transmissão ou distribuição, o que torna possível a competição no segmento de comercialização, dado o baixíssimo custo de entrada e de saída.

No tipo de modelo que está sendo implementado no Brasil, o segmento de distribuição ficaria com a função de distribuir a energia, alugando as redes. Desse modo, a função do segmento de comercialização é negociar diretamente com os consumidores, oferecendo energia do mercado spot, das distribuidoras locais e de outras, não ficando na estrita dependência do distribuidor local. ${ }^{12}$ Logo, a reestruturação da indústria, no que diz respeito à separação do segmento de distribuição/comercialização, torna a atividade de venda direta aos consumidores livres um mercado contestável. Sendo o

\footnotetext{
${ }^{9}$ Embora existam custos fixos, não existem custos irrecuperáveis.

${ }^{10} \mathrm{Da}$ análise aqui efetuada, o custo de saida é um dos aspectos mais importantes Como os ativos sâo muito específicos, a saída total de um mercado dificilmente resultaria na reutilização de tais ativos, o que implica custos irrecuperáveis. Todavia, a competição analisada aqui não estaria associado à perda total do mercado, e sim de alguns consumidores.

"As empresas de comercialização pagam aluguel pelo uso das redes de transmissão e de distribuição para atender seus clientes.

${ }^{12} \mathrm{Na}$ prática, o que seria objeto de competição potencial não seria a concessão (prestação da totalidade do serviço), e sim os consumidores livres (ou não regulados), que podem escolher de quem desejam receber sua energia elétrica.
} 
conceito de competição potencial aplicável ao segmento da indústria que atende a este tipo de consumidor. ${ }^{13}$

A questã́o da barreira à entrada/saída, no caso da comercialização (varejo), estaria na estrita dependência da regulamentação. Uma vez que a nova regulamentação objetiva a competição, esta retira as possíveis barreiras institucionais que poderiam existir, incentivando a competição neste segmento. Resta saber se a competição nos termos acima seria suficiente para gerar a eficiência na indústria. Tal problema estaria associado, principalmente, ao preço a ser cobrado ao consumidor final. Segundo Baumol \& Sidak (1995, p. 28), nos Estados Unidos "a crescente competição no mercado atacadista de geração de energia, junto com a exigência de venda por atacado, vem desafiando o esquema de correção de preços para a transmissão de energia elétrica. " Isto é um grande problema para o órgão regulador ordenar o acesso à rede e regular as tarifas cobradas para o uso de tais redes.

\section{A relação custo do livre acesso e o grau de competição}

Visto que a reforma que está sendo implementada na indústria de energia elétrica, minimiza os efeitos dos sunk costs e permite o livre acesso de todos os agentes (geradores, comercializadores e consumidores livres) às redes de transmissão e distribuição, os efeitos da competição potencial sobre a eficiência da indústria teria também uma relação entre o custo do livre acesso ao mercado e o grau de competição daí decorrente. O nível de preço praticado, além de ser importante para efeito da avaliação da eficiência, é um elemento importante para a caracterização do grau de competição que pode ser alcançado em uma dada indústria.

A propósito, a regra do componente de preço eficiente, também conhecida por regra de Baumol \& Willing, é fundamental para a análise deste problema. Em tal regra, muito bem caracterizada em Armstrong \& Vickers (1996), tem-se que:

$p^{*}=c^{\prime}+a$

onde: $p^{*}$ é o preço ótimo de acesso às redes;

$c$ ' é o custo marginal (direto) de prover o acesso; e,

$a$ é o custo oportunidade de facilitar $\mathrm{o}$ acesso.

\footnotetext{
${ }^{13}$ Os consumidores livres podem ser atendidos tanto por empresas varejistas de energia quanto por produtores independentes (geradores).
} 
No caso da indústria de energia elétrica, o valor de c' está diretamente relacionado ao custo do transporte de energia, o que inclui o custo de transmissão e de distribuição, que será controlado fortemente pelo governo, e seria o mesmo para todos os consumidores de um mesmo nível de tensão (tarifa equalizada).

Quanto ao custo oportunidade de facilitar o acesso, verifica-se que, no setor elétrico, tal custo pode ser definido, tal como proposto por Armstrong \& Vickers (1996), como o valor do lucro que a firma incumbente deixaria de obter por permitir o acesso a um eventual entrante potencial e decorre da desverticalização da indústria. Assim, visto que grande parte das empresas de comercialização surgirão das atuais distribuidoras (que passariam a ter um preço para o serviço de distribuição, controlado pelo governo, e um preço de comercialização, sujeito à competição), quanto menor for a participação de c' em $\mathrm{p}^{*}$ maior será o grau de concorrência pelos consumidores livres. Ou ainda, quanto mais é representativo para a incumbente o custo de facilitar o acesso, maior tende a ser o grau de competição potencial que pode ser alcançado. Ou seja, o grau de competição pode ser dado por: ${ }^{14}$

$$
\alpha=\frac{c^{\prime}}{p^{*}}
$$

onde:

$$
0 \leq \alpha \leq 1
$$

Observe-se que se $\mathrm{a}=1$, então não haveria competição, ao contrário do que ocorreria quando $\mathbf{a}=\mathbf{0}$.

Na prática, o valor de " $a$ " é maior, quando a firma incumbente estiver atuando nas proximidades do ponto de mínimo da curva de custo médio, visto que, neste caso, o preço praticado desestimularia a entrada de novos concorrentes. Além disso, se a distribuição continua verticalizada, todo o preço final pago pelo consumidor livre estará incluído em c'. Mais: se em um dado local não existem consumidores livres, então $\mathrm{p}^{*}=\mathrm{c}^{\prime}$, uma vez que não haveria motivo econômico para facilitar o acesso.

Por outro lado, quanto maior for o número de consumidores livres de uma dada área de concessão (como acontece hoje em Minas Gerais e em São Paulo), maior deve ser a ação do regulador no sentido de reduzir a

\footnotetext{
${ }^{14}$ Deduzido de um manuscrito elaborado por Santana (1998), o qual é resultado de pesquisa desenvolvida no âmbito do Núcleo de Estudos em Energia Elétrica, membro do PRONEX, no corpo do qual foi desenvolvida a pesquisa relativa à dissertação de mestrado VINHAES (1999).
} 
proporção de "c"'" em "p*".. Em outras palavras, uma menor tarifa de distribuição (ou custo direto do acesso) tornará mais livre o acesso de consumidores e geradoras à rede. Se, além disso, o valor de " $a$ " é significativo (o que significaria as empresas comercializadoras trabalharem com lucro mínimo), maiores serão os benefícios para os consumidores livres e, conseqüentemente, maior será a eficiência do sistema. Dessa forma, se p é o preço praticado pela firma incumbente quando verticalizada ${ }^{15}$ e c é o custo de atender o consumidor final (o que inclui distribuição e comercialização), então a margem de lucro (1) da firma seria:

$$
\ell=\frac{p-c}{p}
$$

Porém, se, alternativamente, a empresa incumbente é desverticalizada, então tem-se que:

$$
\ell=\frac{\left(p^{*}-c^{\prime}\right)-a}{p^{*}}
$$

Da equação acima pode-se deduzir que se o valor de c' (que seria a tarifa de acesso à rede de transmissão) é regulado pelo governo, então o valor da 1 seria uma função de " $a$ ". Dito de outra forma, quanto maior for a participação de " $a$ " na formação do preço final, menor será o valor de 1 . Ou seja, quanto mais o lucro da incumbente está sujeito ao valor de " $a$ ", maior tende a ser a competição potencial, uma vez que menor seria a tarifa de acesso (ou menor seria o valor de c'), como pode ser verificado pela equação 6.1. Isto é, no limite:

$a=c-c^{\prime}$

Observe-se que um maior valor de " $a$ " não significa um maior valor de $\mathrm{p}^{*}$, e sim que maior será a margem de negociação em torno do lucro, visto que no segmento de comercialização quase não existe sunk costs. Ou seja, se $o$ acesso é livre e se quase não há custos encalhados (stranded costs) no segmento de comercialização de energia, então é possível se criar um ambiente de competição em tal segmento e, portanto, a Teoria dos Mercados

${ }^{15}$ Onde $p^{1} p^{*}$ e $c^{1} c^{\prime}$, pois $p$ e c são tratados para o caso de firmas verticalizadas. 
Contestáveis se torna um importante instrumento para formulação das regras de competição.

Esta conclusão nos remete a três deduções interessantes. Em primeiro lugar, a definição da tarifa de acesso às redes não poderia estar sujeita aos efeitos do problema de informações assimétricas. Visto que esta tarifa vai ser definida pela agência reguladora, com base em informações fornecidas pelas empresas, então não deveria haver ambigüidade relativamente à composição dos custos das redes. Em segundo lugar, a criação de instrumentos institucionais que venham aumentar o número de consumidores livres tenderia a elevar o grau de competição e, pelo que foi mostrado na equação (6.4), maximizar os benefícios econômicos para tais consumidores, com efeitos diretos sobre a eficiência do sistema.

Por último, a necessidade de reduzir a participação de "c" " em " $\mathrm{p}$ *" exige a prática de lucros extremamente baixos para as empresas transmissoras e distribuidoras, não obstante a intensidade de capital inerentes a tais segmentos da indústria. Dito de outra forma, os monopólios de transmissão e distribuição devem ser regulados (ao máximo), o que sugere a manutenção dessas empresas como propriedade estatal.

\section{Conclusão}

Tratar a contestabilidade na prática, significa, em outras palavras, dizer em que grau a competição vai ocorrer de forma efetiva e potencial na indústria de energia elétrica brasileira, principalmente no segmento de comercialização (varejo), foco central deste trabalho.

As experiências de outros países, como são os casos inglês, americano e argentino, entre outros, têm mostrado a efetividade da escolha dos consumidores em relação aos seus distribuidores e uma melhora da eficiência deste segmento. Entretanto, esta melhora tem se apresentado de forma distinta. Por exemplo, no caso Argentino a melhora tem sido percebida em termos de eficiência econômica geral (alocativa, distributiva, produtiva). No caso inglês, apesar de ter melhorado a eficiência (distributiva e produtiva), não se verificou repasse de ganhos de produtividade aos consumidores. $\mathrm{Na}$ verdade, a tarifa até aumentou, comprometendo a eficiência alocativa. ${ }^{16}$

Sem dúvida, dadas as características do parque gerador brasileiro, o grau de competição para toda a indústria vai ser menor do que nos demais países. No segmento específico de distribuição/comercialização, a competição deve seguir o mesmo caminho do caso inglês, chileno e argentino,

\footnotetext{
${ }^{16}$ Maiores detalhes sobre os resultados dos demais paises ver VINHAES (1999).
} 
entretanto em um grau bem menor. Na Inglaterra, onde a reforma se encontra num estágio bem mais avançado, o grau de competição atinge praticamente todas as classes de consumidores, já que a concorrência potencial e efetiva prevalece e se confunde.

No Brasil, a competição potencial e efetiva vai atingir, num primeiro momento, cerca de $15 \%$ da demanda total de energia elétrica, sendo incluído neste número cerca de 2.000 consumidores que consomem energia acima de $10 \mathrm{MW}$, a uma tensão superior de $69 \mathrm{KV}$ (os consumidores livres). A partir do ano 2000 , a regulamentação baixa esse limite para $3 \mathrm{MW}^{17}$, possibilitando a entrada de cerca de $30 \%$ do consumo de energia elétrica. Os consumidores que estão fora desse limite vão continuar como consumidores cativos, sujeitos à oferta de energia por parte de distribuidoras locais, e os preços estarão regulados no regime de price-cap.

As evidências, ainda no Brasil, mostram perspectivas bem interessantes. Por exemplo, dado que os geradores já estão competindo para vender energia às atuais distribuidoras e também aos consumidores livres, observase que os custos marginais de expansão do parque gerador estão, hoje, bem menores do que aqueles calculados pelo Grupo Coordenador da Expansão dos Sistemas - GCPS --, da Eletrobrás, em 1995, quando este elaborou o plano 2005. Naquela época, o custo marginal de expansão era de US\$ 40/ MWh. Hoje, as últimas usinas que foram licitadas e que estão sendo construídas pela iniciativa privada têm custos bem menores: ${ }^{18} \mathrm{RS} 38 / \mathrm{MWh}$, na térmica de Uruguaiana; $\mathrm{R} \$ 48 / \mathrm{MWh}$ na hidrelétrica de Lajeado e $\mathrm{R} \$ 41$ / MWh na hidrelétrica de Cana Brava. ${ }^{19}$

Ainda que possa parecer possível a criação de um ambiente competitivo na indústria de energia elétrica, o sucesso da competição, na prática, depende de uma série de fatores. Por exemplo, no Brasil não existe tradição para a compra de energia de empresas comercializadoras, isto é, sem instalações físicas de distribuição. Assim, ainda que seja um mercado que pode ser contestável, é muito provável que a competição não ocorra no grau esperado pelo governo, dada a baixa representatividade dos consumidores livres e a falta de tradição, tanto dos consumidores quanto das empresas incumbentes.

\footnotetext{
17 Os consumidores de classe comercial, como os grandes shopping-centers, podem formar cooperativas de consumidores e escolher também suas geradoras, isto tem ocorrido no Rio de Janeiro.

${ }_{18} \mathrm{O}$ valor do custo marginal do GCPS seria $\mathrm{R} \$ 48 / \mathrm{MWh}$, para uma taxa de câmbio de US\$ $1,00=$ $\mathrm{R} \$ 1,20$.

${ }^{19}$ No caso das empresas hoje distribuidoras, muitas delas já estão se preocupando com a perda de consumidores livres, o que as está levando a pelo menos não aumentarem as tarifas para estes consumidores. Já há um caso, da ESCELSA, no Espírito Santo, em que a tarifa foi reduzida, em Setembro de 1998 , em cerca de $2 \%$.
} 
Vale lembrar, ainda, que o formato dos contratos pode ser uma fator de inibição para a competição, uma vez que o consumidor livre deve avisar com antecedência ao seu atual fornecedor que pretende rescindir o contrato de compra de energia e mudar de fornecedor. Se o prazo do contrato é muito longo, acima de dois anos, como é atualmente, isto vai impedir, em certo grau, a liberdade de escolha do consumidor, inibindo a competição, visto que representaria um aumento dos custos de saída. Neste sentido, o órgão regulador deve estar atento ao prazo de duração dos contratos, não deixando que este passe do limite de dois anos, e reduzindo o prazo para o consumidor efetivar a sua escolha rescindindo o contrato vigente.

Sob o ponto de vista da Teoria dos Mercados Contestáveis, avaliar instrumentos da reforma consistiu, basicamente, em analisar se os pressupostos de tal reforma asseguram a livre entrada e a livre saída dos agentes e se os sunk costs não seriam um elemento impeditivo para a concorrência potencial. Verificou-se, no caso, que a proposta de desverticalização do segmento de distribuição pode estimular a competição entre as empresas comercializadoras, visto que tal desverticalização assegura o livre acesso (às redes de distribuição), facilitando a entrada de novos competidores e, ao mesmo tempo, (praticamente) eliminando os sunk costs relacionados com os sistemas de distribuição, facilitando saída com baixíssimos custos.

Nessa análise, ex-ante, conclui-se que, teoricamente, a reforma da indústria de energia levaria a um ambiente mais competitivo, contudo, provavelmente com um grau de competição bem menor com relação àquele que tem ocorrido nos outros países onde foram introduzidas reformas semelhantes dadas as limitações dos instrumentos regulatórios, que atingem apenas parte dos consumidores, a competição pode ser pouco significativa, sobretudo se comparada com o que tem ocorrido em outros países ${ }^{20}$.

\section{Referências bibliográficas}

ARMSTRONG, M. \& VICKERS, J. (1996) The Acess Pricing Problem: a Synthesis. The Journal of Industrial Economics, vol. 44, n. ${ }^{\circ}$ 2, p. 131-150.

BAUMOL, W. J. \& PANZAR, J. C. \& WILLIG, R. D. (1982) Contestable Markets and The_Theory of Industry Structure. New York: Harcourt Brace Jovanovich. BAUMOL, W. \& SIDAK, J, (1995) Transmission Pricing and Stranded Costs in the Eletric Power Industry. The AEI Pess.

\footnotetext{
${ }^{20}$ Nos outros países, este percentual é bem maior. Conforme já mencionado, na Inglaterra quase $100 \%$ dos consumidores podem escolher seus fornecedores, pois neste país a fonte de geração é diferente, com usinas termelétricas, que são mais flexíveis.
} 
CASTELO BRANCO, E. (1996) A Reestruturação e a Modernização do Setor Elétrico_Brasileiro. Revista Nova Economia. Belo Horizonte, v. 6, n. ${ }^{\circ} 01$, julho, p. $105-141$.

COOPERS \& LYBRAND (1997) - Projeto de Reestruturação do Setor Elétrico Brasileiro._Relatório Consolidado Etapa IV-Vol. 1. Sumário Executivo. Brasília, junho de 1997.

COSTA, A. B. (1995) Organização Industrial, Mercados Contestáveis e Política Pública. Texto Didático, UFRGS, p. 1-18.

FONTENELE, A. M. (1996) Das Análises de Bain à Teoria de Mercados Contestáveis. Estudos Econômicos, v. 26, n. ${ }^{\circ} 3$, setembro-dezembro 1996, p. 381-409.

GOMES, A. A. C. (1997) A Reestruturação das indústria de Rede: Uma Avaliação do Setor Elétrico Brasileiro. Dissertação de Mestrado. Universidade Federal de Santa Catarina. Engenharia de Produção.

OLIVEIRA,C. A. V. (1998) O Surgimento das Estruturas Hibridas de Governança na Indústria de energia Elétrica Brasileira: Uma abordagem Institucional da Economia dos Custos de Transação, Dissertação de Mestrado em Economia, UFSC,

POSSAS, M. L. \& PONDÉ, J. L. \& FAGUNDES, J. (1997) Regulação da Concorrência nos_Setores de Infra-estrutura no Brasil: um enfoque alternativo. Anais do XXII Congresso da ANPEC, Recife- outubro de 1997. p. 1446-1465.

SANTANA, E A. \& Oliveira, C. A. V. (1998) Regulação e Coordenação: Duas Fontes de_Ineficiência na Indústria de Energia Elétrica Brasileira - NEEE/ PRONEX/UFSC 1998, p. 1-20.

VINHAES, E. A. S. (1999) A Reestruturação da Indútria de Energia Elétrica Brasileira: Uma Avaliação da Possiblidade de Competição Através da Teoria de Mercados Contestáveis. Dissertação de Mestrado - Centro de Pós-Graduação em Economia - Universidade Federal de Santa Catarina - Florianópolis, Fevereiro 1999. 